UDK 784.6(497.12) Osterc

\title{
NOVO V MLADINSKIH ZBORIH SLAVKA OSTERCA
}

\author{
Katarina Bedina (Ljubljana)
}

V zadnjih dvajsetih letih vse pogostejši orisi osebnosti Slavka Osterca, analize nekaterih njegovih del in oživljanje podobe doslej najbolj hrupnega, udarnega in vplivnega novotarja $\mathrm{v}$ vrstah slovenskih glasbenikov, postopoma luščijo tega, še danes ne povsem osvojenega ustvarjalnega duha. Odmerjajo mu težo, kompozicijsko-slogovni in vzgojni pomen na domala vseh področjih našega predvojnega glasbenega življenja. Vrednotenje Osterčevega preloma z romantičnim izročilom, njegove niti za hip omahujoče zahteve po sodobnem in izvirnem zvočnem izražanju, oris umetnikovih jasnih ustvarjalnih načel, zavestnega odklanjanja tradicije, pojasnjevanje za njegov čas resnično drznih kompozicijskih sredstev ter avantgardnega mišljenja, vse to je $\mathrm{v}$ glavnih obrisih že odmerilo skladateljev ugledni delež $\mathrm{v}$ novejši slovenski glasbi.

$\mathrm{K}$ temu sta prispevala časovna razdalja in današnje pojmovanje novega zvoka, odnosa do takoimenovane svobodne oblike, kopičenja disonanc, nenavadnih harmonskih postopov (danes: netematske in izventonalne gradnje) ter sploh do estetike, ki se je žolčno spopadala z vsem, kar je presegalo okvir tradicionalnega ustvarjanja. Danes prav tako ni več vprašanj o pravilnosti ali zgrešenosti Osterčeve skladateljske usmeritve. Vedno bolj se kaže kot docela utemeljena in predvsem kot posledica ustvarjalne nuje, ki se je začela $s$ polnim razmahom sproščati ob pravem času: $z$ nastopom velikih znanilcev nove glasbe, zgodnjim Stravinskim, Hindemithom, deloma Prokofjevom in Bartókom. $\mathrm{Z}$ njimi so dobila Osterčeva ustvarjalna hotenja (nasprotna tedanjim in tudi poznejšim ocenam, da je hotel biti sodoben za vsako ceno) tisto izrazno območje, ki je bilo blizu njegovemu glasbenemu doživljanju in mišljenju, kjer je našel, ne glede na popoln odklon javnosti in kritike, vire za razvoj svoje glasbene govorice, $\mathrm{v}$ dosežkih današnjih klasikov moderne pa umetniške vzore. Tudi trmasto hlastanje, pogosto celo pretirano navduševanje nad vsem, kar se je pojavilo $\mathrm{v}$ glasbi novega, se kaže kot nujna posledica ustvarjalnega prepričanja in umetnostnih nazorov, podkrepljenih z njegovim značajem in temperamentom. Pripadnost tedanji glasbeni avantgardi je tako povsem razumljiva in logična, v slovenskih razmerah pa je učinkovala kot "brez- 
obzireni revolucionarni pojav z izredno pomembnim razvojnim vplivom. Vendar tu začenja manj razgrnjena stran Osterčevega lika: muzikalna vsebina kot čista umetniška vrednost, vprašanje, kako ji Osterc kroji izrazno novotarstvo, kaj se skriva in kaj sije za njegovo satiro, zbadljivko, šaljivko, njegovim cinizmom, odporom do čutnosti v glasbi, razumskim snovanjem in humorjem.

Pesmi za mladinski zbor so droben, obstranski opus Slavka Osterca, Dvanajst skladbic, če štejemo Belokranjske nagajivke kot eno bibliografsko enoto. ${ }^{1} \mathrm{Ni}$ naključje, da jih je napisal $\mathrm{v}$ zreli ustvarjalni dobi, $\mathrm{v}$ zadnjem desetletju pred smrtjo. Pomembno je, da je del svojih moči posvetil mladinski glasbi, z vsemi predznaki svojega jezika, da mu naprednih estetskih nazorov pri tem opusu ni bilo treba posebej utemeljevati. Nastanek Osterčevih pesmi za mladinski zbor je povezan s časom velike preobrazbe slovenskega mladinskega petja, z njegovim doslej najbolj revolucionarnim obdobjem, ki je v jedru spremenilo odnos do načina ustvarjanja za otroke. $\mathrm{Na}$ zunaj ga označuje dragoceno vzgojno, uredniško in pevovodsko delo Srečka Kumarja ter njegovih sotrudnikov, Ivana Grbca, Avgusta Šuligoja, Cirila Preglja in Maksa Pirnika, z njim rojstvo številnih mladinskih zborov po Sloveniji z umetniško osveščenimi vođitelji, navznotraj pa predvsem nova glasba, najprej Adamičeva, potem enkratna Kogojeva, s svežo, muzikalno dognano vsebino, $\mathrm{z}$ mojstrskimi upodobitvami otroške poezije $\mathrm{v}$ poznoromantičnem slogu. ${ }^{2}$ Vzrok za to, da je Osterc pozno in sploh začel pisati za mladinski zbor, je našel Pavel šivic $\mathrm{v}$ skladateljskem načelu. piši za zasedbo in sestave, ki ti zagotove izvedbo. ${ }^{3} \mathrm{Ne}$ vemo, ali je Osterc napisal svoje prvence za otroški zbor na neposredno Kumarjevo spodbudo $^{4}$ (poznejši zbori, razen Novice in študije, so vsi nastali po naročilu pevovodij). Za pojav Osterčeve glasbene govorice v naši zborovski literaturi za mlade je bil odločujoč čas, ki je že pred prvim natisom Belokranjskih nagajivk opravil s čitalniško blagozvočno praznino. 5

1 Ančka, bančka, enoglasna pesem s klavirsko spremljavo (Zvonček, XXX/ 1930/31); Novica, dvoglasna s klavirsko spremljavo, 1936, rkp.; naslednje so vse triglasne: Belokranjske nagajivke, 1933 (Andreju, Francetu, Juretu, Vinkotu, Jošu, Vlahu, Tonetu, Butorajcem); Kvartet, 1933; Študija, 1934; Nezgoda ná piru, Delajmo zlata kolesa, Žabica in muha, vse 1937; Ovce in psi, 1938; Mamica, 1938; Oba junaka, Biba leze, štupa-rama, vse 1940. - Razen prve; Novice in študije (slednji še nista bili natisnjeni), so bile kot zbirka objavljene ob odkritju skladateljevega spomenika $v$ Veržeju 1963. Izdal jih je Mladinski pevski festival $v$ Celju, uredil Makso Pirtnik. - V Grlici VI/1960 je izšla zadnja pesem Osterčeve Belokranjske suite za ženski zbor na besedilo Albina Čebularja, ni pa nikakršne dokumentacije, da bi jo bil skladatelj namenil tudi mladinskemu zboru kot je to storil z Novico: pripisal ji je oznako - dvospev za ženski ali mladinski zbor $\mathrm{s}$ klavirsko spremljavo.

2 Prim. Loparnik B., Po stopinjah časa. Uvod k izdaji Kogojevih Pesmi za mladino ob petdesetletnici Kumarjevega zbornika „Otroških pesmi», Grlica XVI, 1973/74, št. 3-5.

3 Šivic P., Mladinski zbori Slavka Osterca. Ob zbirki Osterčevih mladinskih zborov. Grlica, IX, 1963, št. 4-5.

4 Prvič so bile natisnjene $\mathrm{v}$ trojni številki (zvezek VIII, IX, X) »Grlice», revijalne zbirke mladinske glasbe Srečka Kumarja, ki je izhajala $v$ Zagrebu od 1933-35.

5 Prim. Loparnik B., ibid. 
osebnosti, temperamenta in glasbenih nazorov, v a cappella glasbi pa jih je utrjeval že $\mathrm{v}$ mešanih in moških zborih. ${ }^{13}$ Analiza besedila in skladb kaže medsebojno sorodnost $\mathrm{v}$ izrazu in obliki. Melodični dikciji posveča Osterc največ skrbi. Povsem jo opira na besedni metrum. Dviganje in padanje melodične linije uravnava po vsebinsko poudarjenih zlogih, vođi jo po zaporedju majhnih intervalov (največkrat v sekundnih postopih), razen ob nenadnih smiselnih preskokih, klicih ali pri redkem onomatopoetskem ponazarjanju. Pri njem ni sledu o izpeljavanju motivov in daljših glasbenih domislekov; vedno ustvarja nove, v skladu $\mathrm{z}$ deklamacijo besedila. Melodična linija je težišče Osterčevega navdiha, oblikuje jo v strnjenem loku, brez refrenov in sekvenc, kot osrednje izrazno sredstvo, ki ga ritem in harmonija le dopolnjujeta. Nastopa kot dognana, izbrušena osnova skladbe, z njo se največkrat približa umetniškemu idealu, kjer ni nobene note ne preveč ne premalo. Nekaj primerov:
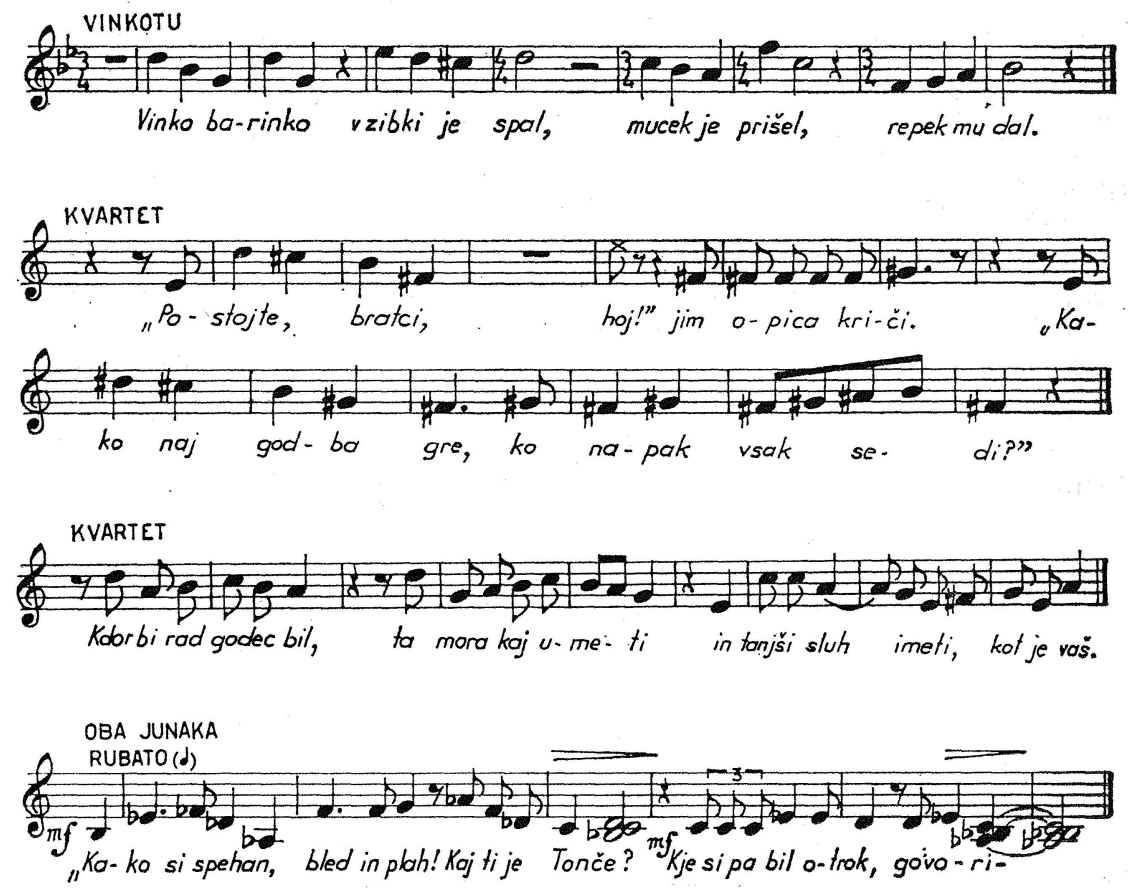

Tekoč in sproščen melodični tok, kot odlika vse dobre pevne glasbe iz vokalnega izročila, $\mathrm{z}$ intuicijo poglobljena besedna predloga, pomembno razširjen izrazni domet pesmi, ki jim v razširjenem, svobodno pojmovanem tonalnem območju, vse to s sodobnimi harmonskimi in ritmičnimi prvinami ustvarja novo, čisto muzikalno vrednost. V Osterčevem opus $u$ za mladinski zbor ne najdemo primera, kjer bi se skladateljeva melodična zasnova pesmi bistveno ne ujemala $s$ to označbo.

1s Do prvencev za mladinski zbor je napisal 11 mešanih in 3 moške zbore. 
O »dopolnilnih izraznih sredstvih", kot jih je Osterc imenoval, je nekaj tudi sam povedal: "Vedno sem pri glasbi ritmu dajal prednost pred harmonijo in polifonijo. Plesne ritme podcenjujem ... zdijo se mi šablonski. V ritmu vidim največji kos originalnosti ... življenje, radost, komiko.. ${ }^{14}$ In: "Meni osebno je harmonija postranskega pomena ... najmanj bistveni del invencije ter jo prištevam le $\mathrm{k}$ tisti neizogibni tehniki, brez katere ne more nastati nobeno mojstrsko delo. ${ }^{15}$ Obe pojasnili sta za Osterca značilni, odražata se tudi $\mathrm{v}$ mladinskih pesmih, seveda $\mathrm{v}$ obsegu in možnostih tega opusa. Ritem je pester, pogojen $\mathrm{v}$ besedni metriki. Raznolika vsebina, zgoščen izraz pesmi in menjavanje drobnih razpoloženjskih odtenkov, ponujajo Osterčevemu navdihu številne ritmične zveze, ki pod njegovim peresom zaživijo tudi $\mathrm{v}$ trenutkih, ko jih beseda le megleno nakaže. Osnovne notne vrednosti so skoraj v enakem razmerju četrtinke in osminke, polovinke le $\mathrm{v}$ pesmi Delajmo zlata kolesa, ki ima označbo "kakor koralı. Poredko se pojavijo gibanja v šestnajstinkah in triolah, medtem ko imajo sinkope in punktirani ritmi pomembno vlogo, ponekod je ritmično gibanje podčrtano $\mathrm{z}$ ostinatnimi drobci $\mathrm{v}$ altu, novost, ki je naša mladinska pesem pred Ostercem tudi ni poznala. Ritem se v Osterčevih skladbah, podobno kot melodika, ob vsaki priložnosti izogne ponavljanju, ${ }^{16} \mathrm{v}$ označenih ali neoznačenih taktovskih načinih je zamišljen kot samostojna gibalna sila.

Osterčeva linearna gradnja je kljub novim prijemom dvignila mnogo manj prahu kot njegova akordika. Spotikali so se ob njegove disonance, dodajanje sekund, češ da je to delal zato, da je zvenelo moderno. Zakaj je tako ravnal tudi na nekaterih mestih, kjer vodenje melodične linije in vsebina besedila nista zahtevali zvočne zaostritve, še ni pojasnjeno, kljub odmaknjenemu času in poskusom objektivnega vrednotenja. Od treh primerov, ki so vsi ob sklepih fraz, se zdi muzikalno prepričljiv le prvi:

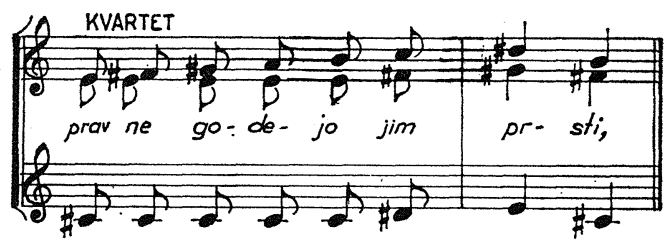

OVCE IN PSI

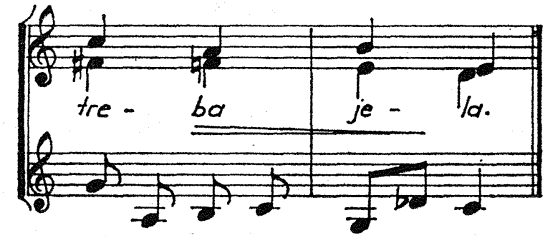

14 Gledališki list ljubljanske Opere, 1938/39, št. 4, str. 27.

15 Osterc S., Glavne struje sodobne glasbe in njih eksistenčna upravičenost, Nova muzika 1928/I, št. 1, str. 3.

16 Izjema je študija, za izvedbo najbolj zahtevna med vsemi, svobodno pojmovana fuga $v$ enotnem, dosledno binarnem ritmu. 


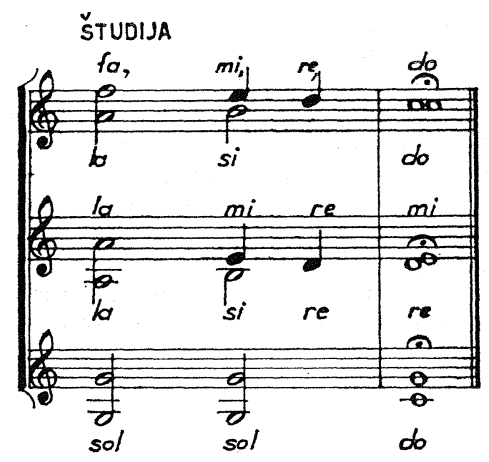

V Belokranjskih nagajivkah je Osterc še označil osnovno tonaliteto skladbe, $v$ poznejših ne več, ker je $\mathrm{v}$ njih močno zabrisana z nastajanjem občasnih tonalnih središč, ${ }^{17}$ brez klasičnih kadenčnih ali modulacijskih prehodov. V Osterčevem in novejšem času se je za to harmonsko zasnovo razširil nedoločni izraz uatonalni slog»; neustreznost tega izraza je Šivic smiselno pojasnil $\mathrm{v}$ razlagi Kvarteta, češ da ne gre za atonalnost, temveč za izventonalni vtis skladbe, ki ga skladatelj doseza $\mathrm{s}$ hitro, neperiodično menjavo tonalno jasnih odstavkov. ${ }^{18}$

Nekateri Osterčevi mladinski zbori (Belokranjske nagajivke, Kvartet, Studija, Stuparama, Biba leze) so kljub namernim disonancam in zavestno ustvarjeni nesimetričnosti $\mathrm{v}$ vseh prvinah stavka taki, da dajejo vtis spontano zrasle oblike, kjer linearna zasnova kot po naključju izzove akordiko in to ne $\mathrm{v}$ funkciji harmonske osnove, marveč kot vsebinsko (izrazno) dopolnilo $\mathrm{v}$ melodiki pogojene invencije. Posebno močan je ta vtis ob sočasnem zvenjenju glasov $\mathrm{v}$ svobodnih imitacijah, $\mathrm{v}$ daljših, večkitičnih pesmih (Kvartet) pa se razteza tudi na vmesne homofonske odstavke. Tu občutimo vertikalno gradnjo popolnoma neprisiljeno, a krepko $\mathrm{v}$ vajetih skladateljeve ustvarjalne volje; disonančne akordične zveze, pripravljene ali nenadne, se skladno družijo $\mathrm{z}$ vsebinsko zadeto melodiko $\mathrm{v}$ zaokroženo celoto - glasbeno misel, jedrnato, v izrazu sodobno, Osterčevo. Verjetno je $\mathrm{v}$ tem, poleg odlik same melodične zasnove, skladateljev umetniški dosežek v opusu za mladinski zbor najvrednejši, samosvoj, nov v najboljšem pomenu besede, delo pristnega muzika in mojstra nove glasbene govorice.

\section{SUMMARY}

Relatively numerous studies of Slavko Osterc's personality have, in conjunction with analyses of his works, considerably elucidated this most influential and penetrating modernist in Slovene music. Less light, however has been shed on Osterc's pure musical qualities, or rather, on how these qualities stand in relation to his musical modernism; in other words: what is characteristic of and what is hidden' behind his satire, comic song, cynicism, contempt for sentimentality, intellectual composing and humour.

17 Skladatelj jih imenuje "centralni harmonični toni». Prim. Osterc S., $O$ sodobni smeri zborovskih skladb, Zbori, IV/1928, št. 1 str. 3.

18 Šivic P., ibid. , 
Osterc's songs for youth chorus represent a tiny by-opus of twenty little songs written in 1930-40; nevertheless, they reflect the modernism typical of his whole work. They are distinguished by contemporary compositional elements, based mainly on concise and funny texts originating mostly from folk-songs of Bela Krajina, by masterly modelled melodic diction, free form, athematic structure, frequent imitative movement of voices, by progressions of dissonant chords, efforts towards new musical expression and by variegated, quite often very quick, changes in rhythm. Regarding Slovene youth music, Osterc's little compositions represent a qualitative shift from a predominantly lyrical, children's way of experience, mostly of a romantic nature, to a concise fable, full of musical cleverness and witty humour suitable for children. 